\title{
Novel Bi- and Trifunctional Inhibitors of Tumor- Associated Proteolytic Systems
}

\author{
Janna Krol', Sumito Sato ${ }^{1,2}$, Peter \\ Rettenberger ${ }^{2}$, Irmgard Assfalg-Machleidt ${ }^{3}$, \\ Manfred Schmitt', Viktor Magdolen ${ }^{1}$ and \\ Ulla Magdolen ${ }^{1, *}$ \\ ${ }^{1}$ Klinische Forschergruppe der Frauenklinik der \\ Technischen Universität München, Klinikum rechts der \\ Isar, D-81675 München, Germany \\ 2 Oxford Brookes University, School of Biological and \\ Molecular Sciences, Oxford OX3 OBP, UK \\ ${ }^{3}$ Adolf-Butenandt-Institut für Physiologische Chemie, \\ Ludwig-Maximilians-Universität München, \\ D-80336 München, Germany \\ ${ }^{*}$ Corresponding author
}

Serine proteases, cysteine proteases, and matrix metalloproteinases (MMPs) are involved in cancer cell invasion and metastasis. Recently, a recombinant bifunctional inhibitor (chCys-uPA ${ }_{19-31}$ ) directed against cysteine proteases and the urokinase-type plasminogen activator (UPA)/plasmin serine protease system was generated by introducing the uPA receptor (uPAR)-binding site of UPA into chicken cystatin (chCysWT). In the present study, we designed and recombinantly produced multifunctional inhibitors also targeting MMPs. The inhibitors comprise the $\mathrm{N}$-terminal inhibitory domain of human TIMP-1 (tissue inhibitor of matrix metalloproteinase-1) or TIMP-3, fused to chCys-uPA ${ }_{19-31}$ or chCysWT. As demonstrated by various techniques, these fusion proteins effectively interfere with all three targeted protease systems. In in vitro Matrigel invasion assays, the addition of recombinant inhibitors strongly reduced invasion of ovarian cancer cells (OV-MZ-6\#8). Additionally, OVMZ-6\#8 cells were stably transfected with expression plasmids encoding the various inhibitors. Synthesis and secretion of the inhibitors was verified by a newly developed ELISA, which selectively detects the recombinant proteins. Invasive capacity of inhibitorproducing cells was significantly reduced compared to vector-transfected control cells. Thus, these novel, compact, and small-size inhibitors directed against up to three different tumor-associated proteolytic systems may represent promising agents for prevention of tumor cell migration and metastasis.

Key words: Cysteine protease/Serine protease/Matrix metalloproteinase/Tumor invasion/Urokinase receptor.

\section{Introduction}

Cancer cell invasion and metastasis are multistep processes that require coordinated series of anti-adhesive, adhesive, migratory, and proteolytic events. Major proteases involved in these tumor cell-associated processes are matrix metalloproteinases (MMPs), cysteine proteases (e.g. cathepsin B and L), and serine proteases [e.g. the urokinase-type plasminogen activator (uPA)/plasmin system]. These proteolytic systems also interact and thereby efficiently activate each other. This may result in detachment of cancer cells from the primary tumor, followed by migration through the extracellular matrix, intra- and extravasation, and eventually metastasis formation in distant organs (Magdolen et al., 2000).

Already in the 1970's, Reich and his collaborators showed that increased secretion of plasminogen activator (PA) by tumor cells is largely responsible for enhanced extracellular proteolytic activity associated with malignancies (Reich, 1978). Following this early observation, a number of subsequent studies reported on the correlation between elevated levels of UPA in primary tumor and cancer progression. In a variety of malignancies, UPA antigen emerged as a strong, independent, statistically significant prognostic factor for both disease-free and overall survival. Increased expression of the uPA receptor (UPAR) and of the plasminogen activator inhibitor type-1 (PAI-1) in the primary tumor also correlates with a highly invasive phenotype and poor prognosis of several tumor types (for reviews see Andreasen et al., 1997; Reuning et al., 1998; Schmitt et al., 2000; Muehlenweg et al., 2001).

Accumulation of the proteolytic activity at the leading edge of a tumor is an essential feature to allow tissue invasion of many tumor cells. Moreover, binding of uPA to its receptor activates cell migration via induction of chemotaxis and regulation of cell adhesion, and has a stimulatory effect on cell proliferation both directly, through the activation of cell-signaling pathways, and indirectly, e.g. via the activation of latent forms of growth factors by plasmin (Reuning et al., 1998; Andreasen et al., 2000). Furthermore, there is also some evidence for an involvement of the uPA-system in vascular remodeling (Rabbani and Mazar, 2001).

Another group of proteolytic enzymes that plays an essential role in tumor progression is the matrix metalloproteinase (MMP) family (Stamenkovic, 2000). These proteases collectively degrade structural components of the extracellular matrix and of basement membranes, allowing tumor cells to invade the surrounding connective tissue, to enter and exit from blood and lymphatic vessels, 
and thus to metastasize distant organs. Depending on the nature of MMP and available substrate, MMPs can also modulate cell proliferation, adhesion, and migration. A positive correlation between MMP expression and tumor cell invasion and metastasis was demonstrated in vitro as well as in vivo. A variety of studies showed the association of MMPs with the invasive and metastatic behavior of virtually all cancer types (for reviews see Curran and Murray, 1999; Stetler-Stevenson, 2001).

Cathepsin B, H and L, which are primarily lysosomal cysteine proteases, are also extracellularly present in elevated amounts in different types of tumors and are - together with the uPA/plasmin system and metalloproteinases - involved in cancer invasion by degrading certain extracellular matrix components. In addition to this function, cathepsins may activate precursors of other proteases (Magdolen et al., 2000). A number of reports have indicated that the balance between cysteine proteases and their endogenous inhibitors is changed in tumors. Moreover, in several clinical studies cathepsins and their inhibitors were shown to have a high prognostic impact to predict survival of patients with different tumor diseases (Lah and Kos, 1998).

In view of their important role in tumor invasion and metastasis, the UPAR/uPA/plasmin system, MMPs, and cysteine proteases have become promising therapeutic targets for development of novel anti-tumor drugs. In many studies, peptide and small molecule antagonists were used to block uPA/uPAR-interaction and showed their effectiveness to reduce cancer cell invasion and metastasis both in vitro and in vivo (Fong et al., 2002; Ploug et al., 2002; Schmiedeberg et al., 2002; Sato et al., 2002). Other approaches include down-regulation of uPAR expression using antisense gene therapy and inhibition of the proteolytic activity of UPA by synthetic active-site inhibitors (Mazar, 2001; Sperl et al., 2001). Also, targeting of MMPs with their natural inhibitors, the tissue inhibibitors of matrix metalloproteinases (TIMPs), or synthetic metalloproteinase inhibitors impeded invasion, subsequent metastasis formation, and tumor-associated angiogenesis in different in vitro and in vivo models. These results led to the development of new anti-tumor drugs, currently tested in clinical trials (Stetler-Stevenson, 2001; Coussens et al., 2002). Cystatin C is the strongest human inhibitor of extracellularly released cysteine proteases, it was therefore most frequently investigated in tumor invasion and metastasis. Transfection of tumor cells with cystatin $\mathrm{C}$ cDNA led to an inhibition of tumor cell invasion through an artificial matrix barrier in vitro and to a significant reduction of the number of lung metastases after tail vein injection in nude mice (for a review see Magdolen et al., 2002).

Since these proteolytic systems play an important role in tumor progression and to some extent display overlapping, redundant activities, it seems to be an interesting strategy to modulate their proteolytic activity simultaneously. Recently, bifunctional inhibitors were designed, which on the one hand are directed against the enzymatic activity of cysteine proteases, and on the other hand inhibit binding of the serine protease UPA to its receptor (UPAR) (Muehlenweg et al., 2000). In the present study, we extended our concept by designing bi- and trifunctional inhibitors that are also directed against MMPs. These recombinant inhibitors were biochemically analyzed with respect to their inhibitory activity against MMPs, cysteine proteases, UPA/UPAR-interaction, and in vitro invasion of human ovarian cancer OV-MZ-6\#8 cells. We also generated OV-MZ-6\#8 cell lines which were stably transfected with expression plasmids encoding bi- or trifunctional inhibitors and tested the effects of the endogenously produced and secreted recombinant inhibitors on the invasive capacity of the cancer cells.

\section{Results}

\section{Expression, Purification and Refolding of Multifunctional Inhibitors}

Bifunctional inhibitor molecules were designed which are composed of the inhibitory domains of human TIMP-1 or TIMP-3 (N-hTIMP-1 or -3) fused to chicken wild-type cystatin (chCysWT) and are thus directed against both matrix metalloproteinases and cysteine proteases. Additionally, trifunctional inhibitors were generated, in which a cystatin variant was used that harbors the UPAR-binding site of the UPA molecule $\left(\mathrm{UPA}_{19-31}\right)$ and blocks UPA/UPAR-interaction (Muehlenweg et al., 2000). As an example, the structure of the trifunctional inhibitor $\mathrm{N}$ hTIMP-1-chCys-uPA ${ }_{19-31}$ is depicted in Figure 1.

All four recombinant inhibitors (N-hTIMP-1-chCysWT, N-hTIMP-3-chCysWT, N-hTIMP-1-chCys-uPA ${ }_{19-31}$, and $\mathrm{N}$-hTIMP-3-chCys-uPA 19-31 $_{1}$ ) were expressed in $E$. coli cells (expression rate: approx. $10-15 \%$ of total protein). The introduction of $\mathrm{a} \mathrm{His}_{6}$-tag at the $\mathrm{C}$-terminus allowed purification of the recombinant proteins by use of $\mathrm{Ni}^{2+-} \mathrm{ni}-$ trilotriacetic acid affinity chromatography, yielding a purity of $>95 \%$ under denaturing and reducing conditions (Figure 1). The inhibitors contain structural and functional important intramolecular disulfide bridges; therefore, the purified proteins had to be refolded to obtain biologically active proteins. The protocol used for refolding of N-hTIMP-1-chCysWT and N-hTIMP-1-chCys-uPA 19-31 $_{1}$ (for details see Materials and Methods) was not suitable for refolding of N-hTIMP-3-containing recombinant proteins (more than $90 \%$ of the protein precipitated). After testing different protocols for refolding of the N-hTIMP-3 variants, a modification of the method described by $\mathrm{Ne}-$ gro et al. (1997) was used instead. The highest achievable active concentration of any of the four purified recombinant proteins corresponded to only about $8 \%$ of total protein. The reason for the low recovery of active inhibitors is very likely due to the presence of six disulfide bridges in all four recombinant inhibitors (three in the $\mathrm{N}$ terminal domain of TIMP-1/-3 and three in chCys) that 
have to be correctly formed during the refolding process (Magdolen et al., 2002).

\section{Inhibition of Matrix Metalloproteinases by N-hTIMP-1- or N-hTIMP-3-Containing \\ Recombinant Inhibitors}

The inhibitory capacity of the TIMP-domains of the biand trifunctional inhibitors was tested in MMP activity assays. A representative result is depicted in Figure 2 . The multifunctional inhibitors as well as recombinantly expressed, purified and refolded N-hTIMP-1 significantly reduced the proteolytic activity of MMP-2. With heat-denatured inhibitors added to the wells as negative control samples, inhibition was almost but not completely abolished. The residual inhibitory activity may be due to renaturation of part of the inhibitors after heat-denatura- tion. All multifunctional inhibitors and N-hTIMP-1 were additionally analyzed in MMP-1 and MMP-9 assays and were shown to reduce the activity of both matrix metalloproteinases by about 40-90\% (data not shown).

The inhibitory capacity of the multifunctional inhibitors toward MMP-2 was verified also by reverse zymography. As shown in Figure 3, all inhibitors prevented degradation of gelatin by MMP-2 in the gel matrix, leading to protein staining of non-degraded gelatin at the expected positions of the inhibitors. These bands are not visible in the control gel, which was loaded with the same amount of inhibitors (approx. $0.25 \mu \mathrm{g}$ ) but did not contain gelatin and MMP-2.

In addition to expression in E. coli, the trifunctional inhibitor N-hTIMP-1-chCys-uPA ${ }_{19-31}$ was also produced in the eukaryotic baculovirus expression system. Secretion of the recombinant protein by insect cells was directed

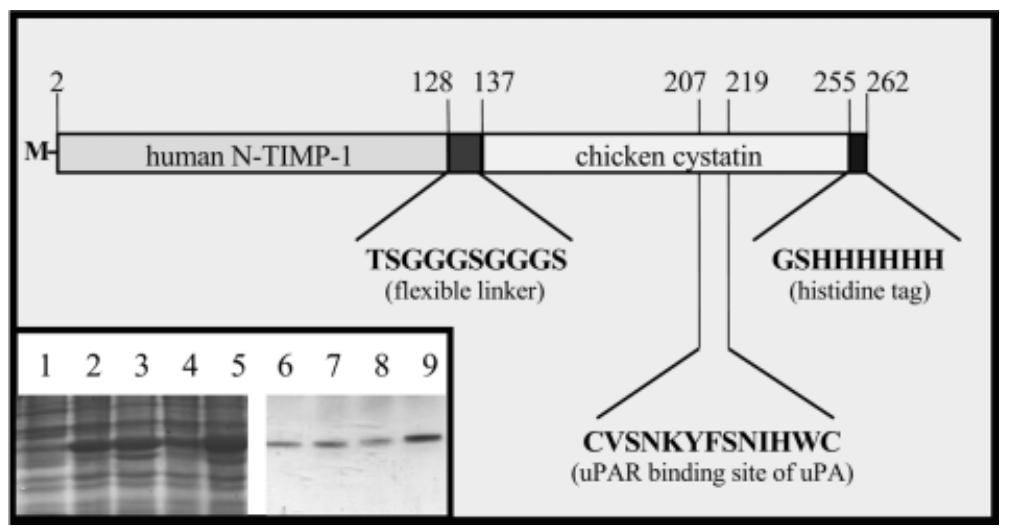

Fig. 1 Structure of the Trifunctional Inhibitor N-hTIMP1-chCys-uPA ${ }_{19-31}$.

The cDNA sequence encoding the N-terminal domain of human TIMP-1 was fused to the DNA sequence encoding chCys-uPA $\mathrm{A}_{19-31}$ and cloned into the bacterial expression vector pQE-60. In a similar manner, the fusion genes encoding N-hTIMP-1-chCysWT, N-hTIMP-3chCysWT, and N-hTIMP-3-chCys-uPA ${ }_{19-31}$ were designed and generated. The inset displays SDS-PAGE analyses of extracts from $E$. coli cells expressing the recombinant chimeric proteins $(2-5)$ and the multifunctional inhibitors after affinity purification (6-9). Lane 1 : cell extract from recipient $E$. coli strain; lanes 2 and 6: N-hTIMP-1-chCysWT; lanes 3 and 7: N-hTIMP-3-chCysWT; lanes 4 and 8: N-hTIMP-1-chCys-uPA ${ }_{19-31}$; lanes 5 and 9: N-hTIMP-3-chCys-uPA 19-31. .

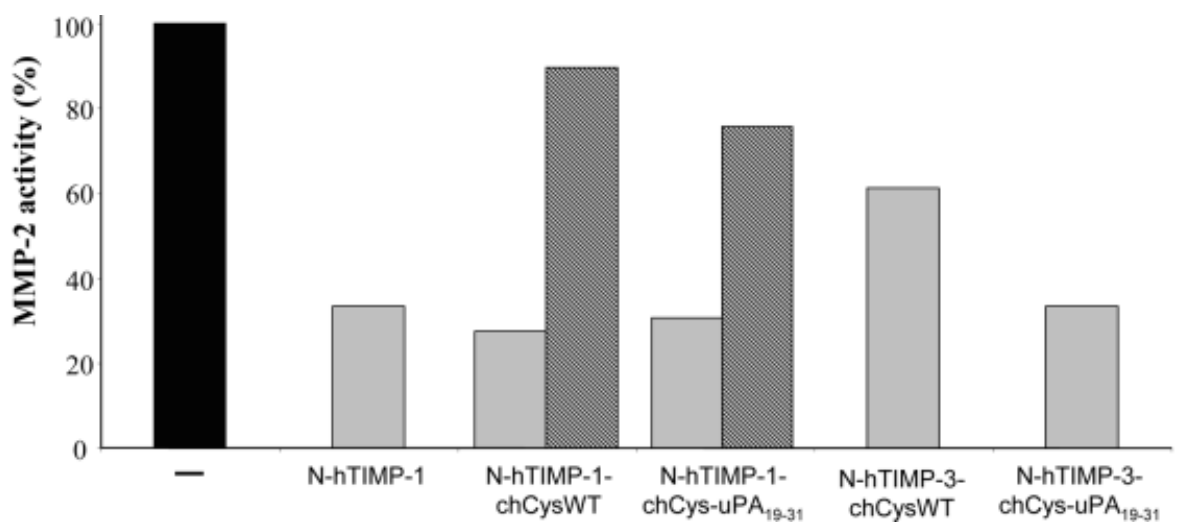

Fig. 2 Activity of Recombinant Inhibitors as Tested by the Biotrak MMP-2 Activity Assay.

$0.5 \mu \mathrm{g}$ to about $2 \mu \mathrm{g}$ of recombinant inhibitors were incubated with activated MMP- $2(6 \mathrm{ng} / \mathrm{ml})$ overnight at $4^{\circ} \mathrm{C}$. Then, the detection enzyme and chromogenic substrate were added and the residual MMP-2 activity was monitored in a spectrophotometer at $405 \mathrm{~nm}$. As a control, N-hTIMP-1-chCysWT and N-hTIMP-1-chCys-uPA $A_{19-31}$ were inactivated at $96^{\circ} \mathrm{C}$ for 10 min prior to incubation with activated MMP-2 (hatched bars). The assays were performed in duplicate for each value. Standard deviations are not depicted, as they were usually less than $1 \%$. 
A

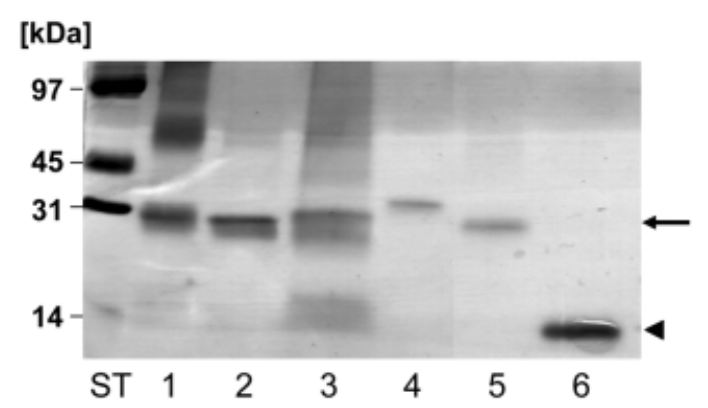

B

[kDa]

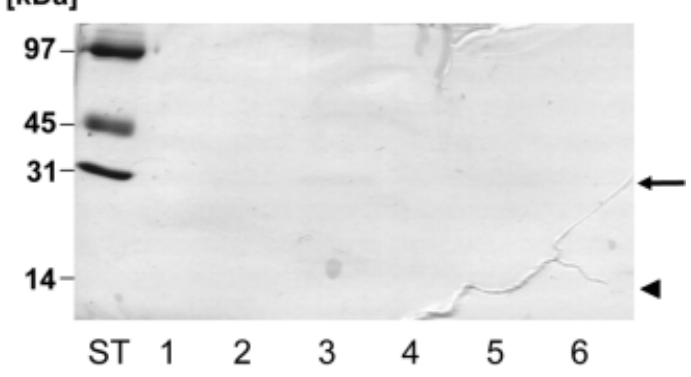

Fig. 3 Reverse Zymography Analyzing the Inhibitory Activity toward MMP-2.

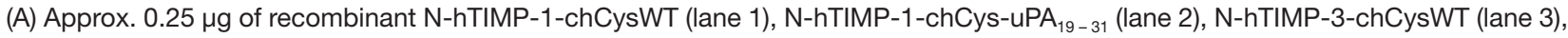

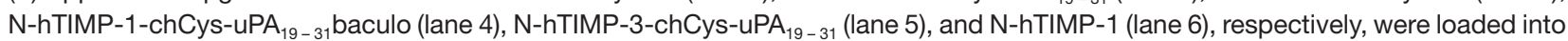
wells of an SDS polyacrylamide gel containing gelatin plus MMP-2. After electrophoresis, SDS was removed from the gel and the gel incubated overnight at $37^{\circ} \mathrm{C}$ in $50 \mathrm{mM}$ Tris- $\mathrm{HCl}, \mathrm{pH} 7.5,5 \mathrm{mM} \mathrm{CaCl}_{2}$ and $5 \mu \mathrm{M} \mathrm{ZnCl}$ for the digestion of the MMP-2 substrate, gelatin. Subsequently, the gel was stained with Coomassie Blue. (B) Control gel lacking gelatin and MMP-2.

A

[kDa]

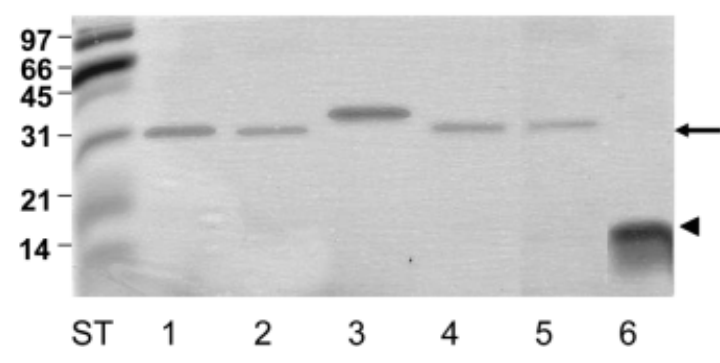

B

[kDa]

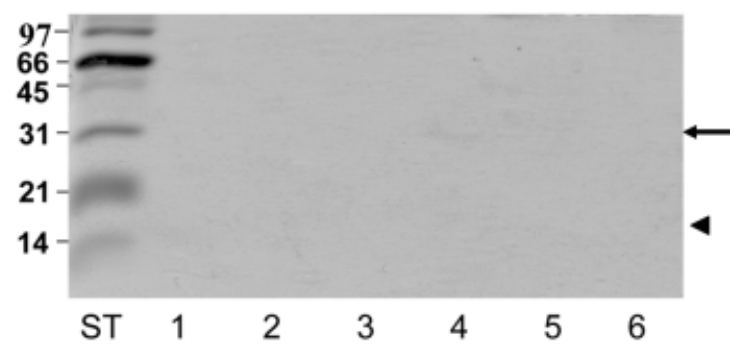

Fig. 4 Reverse Zymography Analyzing the Inhibitory Activity toward Papain.

(A) About $0.25 \mu \mathrm{g}$ of recombinant N-hTIMP-1-chCysWT (lane 1), N-hTIMP-3-chCysWT (lane 2), N-hTIMP-1-chCys-uPA $19-31$ baculo

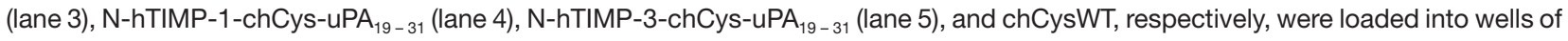
an SDS polyacrylamide gel containing casein. After electrophoresis, the gel was washed extensively to remove SDS and incubated in a solution containing papain for the digestion of the casein substrate. Subsequently, the gel was stained with Coomassie Blue. (B) Control gel lacking casein.

by the natural human TIMP-1 presequence. The protein was purified under native conditions and displayed inhibitory activity against all of the three tested MMPs (MMP-1, -2, and -9) in MMP activity assays. In reverse zymography analyses, this variant (N-hTIMP-1-chCysuPA $_{19-31}$ baculo) shows a slightly elevated apparent molecular mass (Figure 3). As it is produced in an eukaryotic expression system, this is most probably due to glycosylation of the TIMP-1 moiety (Brew et al., 2000).

\section{Inhibition of the Cysteine Protease Papain}

The inhibitory activity of recombinant multifunctional inhibitors toward the cysteine protease papain was also tested by reverse zymography (Figure 4). About $0.25 \mu \mathrm{g}$ of purified and refolded multifunctional inhibitors as well as recombinant chCysWT were subjected to a $0.1 \%$ casein containing SDS polyacrylamide gel electrophoresis. After removal of SDS, the gel was incubated in a buffer containing papain, added to digest its substrate casein. The bands on the Coomassie Blue-stained gel correspond to non-degraded casein at the positions of
chCysWT (approx. $13 \mathrm{kDa}$ ) and multifunctional proteins (approx. $31 \mathrm{kDa}$ ) (Figure 4A). A control gel lacking casein was treated in the same way and showed no bands (Figure 4B). Again, the apparent molecular mass of N-hTIMP1-chCys-uPA ${ }_{19-31}$ produced in insect cells was slightly increased as compared to the corresponding protein synthesized by $E$. coli cells.

In addition, the $K_{\mathrm{i}}$ values of the recombinant proteins for papain were determined (Table 1). Recombinant N-hTIMP-1-chCysWT, N-hTIMP-3-chCysWT, N-hTIMP1-chCys-uPA ${ }_{19-31}$, and N-hTIMP-1-chCys-uPA 19-31 $_{\text {bac- }}$ ulo display $K_{\mathrm{i}}$ values close to that of natural chicken cystatin from egg white, indicating that insertion of the uPA-derived peptide $\left(\mathrm{UPA}_{19-31}\right)$ as well as the presence of the N-terminal domain of TIMP-1/-3 and the C-terminal $\mathrm{His}_{6}$-tag have no negative influence on inhibitory activity towards cysteine proteases.

\section{Interaction of the Recombinant Inhibitors with Cell Surface-associated uPAR}

To investigate whether N-hTIMP-1-chCys-uPA ${ }_{19-31}$ (har- 
boring the UPAR-binding region of UPA) interacts with cell surface-associated UPAR, phorbol 12-myristate 13-acetate (PMA)-stimulated U937 cells were incubated with fluorescently labeled high molecular weight UPA (FITCHMW-uPA) mixed with various concentrations of purified, refolded N-hTIMP-1-chCys-uPA ${ }_{19-31}$, and the resulting cell-associated fluorescence was determined. N-hTIMP1-chCysWT (lacking the uPAR-binding site) served as the control protein. As shown in Figure 5, N-hTIMP-1-chCys$\mathrm{UPA}_{19-31}$ reduced binding of FITC-HMW-UPA to UPAR in a dose-dependent manner whereas N-hTIMP-1-chCysWT did not influence uPA/uPAR-interaction (Figure 5). The

Table 1 Inhibition Constants of Multifunctional Inhibitors toward Papain.

\begin{tabular}{|c|c|}
\hline Inhibitor & $K_{\mathrm{i}}[\mathrm{pm}]$ \\
\hline Natural chCys ${ }^{a}$ & 1.4 \\
\hline chCysWT' & 2.0 \\
\hline chCys-uPA $19-31^{b}$ & 1.9 \\
\hline N-hTIMP-1-chCysWT & 2.0 \\
\hline N-hTIMP-1-chCys-uPA $19-31$ & 1.9 \\
\hline N-hTIMP-1-chCys-uPA ${ }_{19-31}$ baculo & 1.4 \\
\hline N-hTIMP-3-chCysWT & 2.0 \\
\hline N-hTIMP-3-chCys-uPA ${ }_{19-31}{ }^{c}$ & n.d. \\
\hline
\end{tabular}

aThe inhibition constant for natural chCys was taken from Machleidt et al. (1993).

bThe inhibition constants for recombinant chCysWT and chCys$\mathrm{uPA}_{19-31}$, respectively, were taken from Muehlenweg et al. (2000).

cThe inhibition constant of N-hTIMP-3-chCys-uPA ${ }_{19-31}$ could not be determined, because of a too low active concentration of this inhibitor after refolding.
$\mathrm{IC}_{50}$ value of ATF (approx. $15 \mathrm{kDa}$ ) was calculated to be approx. $1.35 \mathrm{nM}$. In the case of N-hTIMP-1-chCys$\mathrm{uPA}_{19-31}$ (approx. $30 \mathrm{kDa}$ ), one has to consider that only $4 \%$ of the purified, refolded protein used in FACS analysis was active (as tested by cystatin activity). Taking this into account, the $\mathrm{IC}_{50}$ value (of the active protein) was about $6.7 \mathrm{~nm}$, i.e. about 5-fold higher as that of the natural ligand ATF.

\section{Simultaneous Interaction of the Recombinant Inhibitors with Papain and MMP-2}

The capacity of multifunctional inhibitors to simultaneously interact with the cysteine proteases and MMPs was assessed by surface plasmon resonance (SPR). For this, the cysteine protease papain was covalently bound to a SPRsensor chip (CM-5). chCysWT, N-hTIMP-1-chCysWT, or N-hTIMP-1-chCys-uPA ${ }_{19-31}$ was allowed to bind to the immobilized papain (Figure 6A), followed by addition of activated MMP-2. MMP-2 bound only to the recombinant inhibitors harboring the N-terminal domain of TIMP-1, but not to chCysWT (Figure 6B). Furthermore, different concentrations of activated MMP-2 were applied to the NhTIMP-1-chCys-uPA 19 $-31_{1} /$ papain complex and a concentration-dependent binding was observed (Figure 6C). Similar data were obtained with N-hTIMP-1-chCysWT (not shown). By applying the BIAcore evaluation software, the binding constants for MMP-2 to the multifunctional inhibitor/papain complex were calculated: $K_{d}[\mathrm{~N}-\mathrm{hTIMP}-1-$ chCys-uPA $\left.{ }_{19-31}\right]=29.5$ nM; $K_{d}[\mathrm{~N}-h$ TIMP-1-chCysWT] = $32.0 \mathrm{~nm}$. These values are in agreement with the $K_{d}$ value of activated MMP-2 to recombinant human TIMP-1 $\left(K_{\mathrm{d}}=\right.$ $28.6 \mathrm{~nm}$ ) previously reported by Olson et al. (1997).

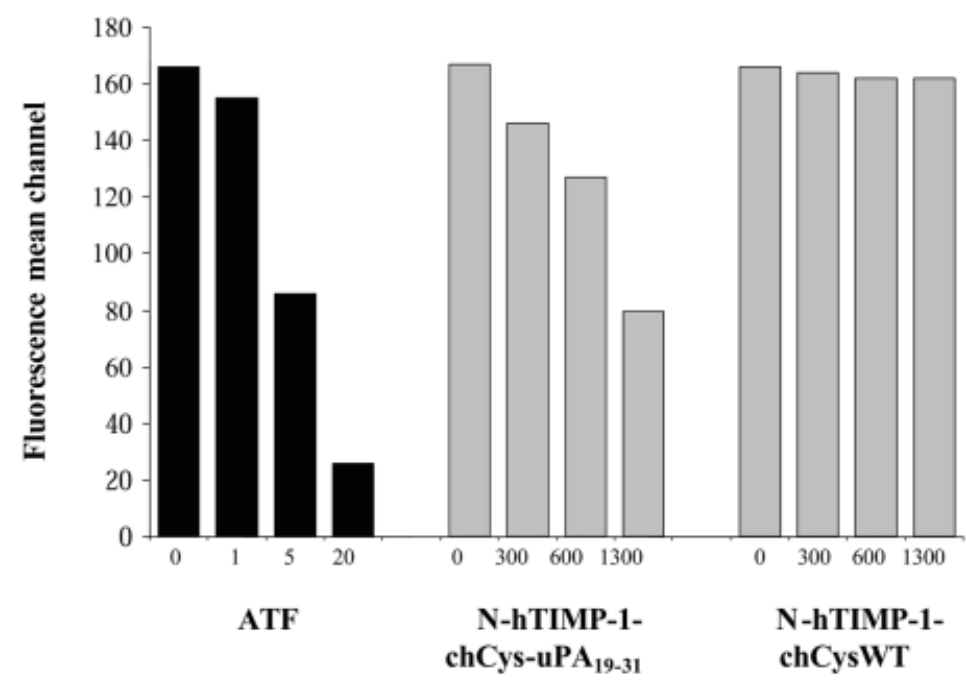

(ng per $250 \mu \mathrm{l}$ per $\mathbf{2 5 0 , 0 0 0}$ cells)

Fig. 5 Interaction of N-hTIMP-1-chCys-uPA ${ }_{19-31}$ with Cell Surface-Associated uPAR Determined by Flow Cytofluorometry (FACS). PMA-stimulated U937 cells were acid-washed to remove endogenous uPA. Then, cells were incubated with FITC-labeled HMW-uPA in the presence of refolded N-hTIMP-1-chCys-uPA ${ }_{19-31}$ or N-hTIMP-1-chCysWT and, subsequently, binding of labeled uPA to cell surface-associated uPAR was analyzed by flow cytofluorometry. N-hTIMP-1-chCysWT did not influence FITC-HMW-uPA binding, whereas N-hTIMP-1-chCys-uPA ${ }_{19-31}$ significantly reduced uPA-binding to uPAR in a dose-dependent manner. The amino-terminal fragment of UPA (ATF) served as a positive control. 
A

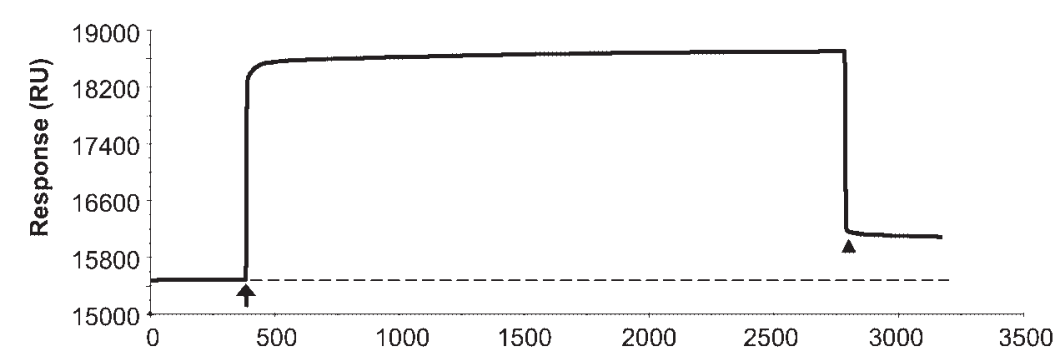

B

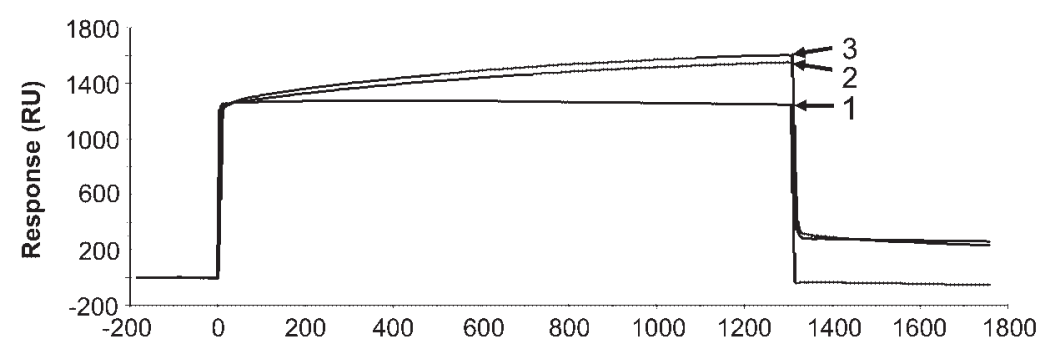

C

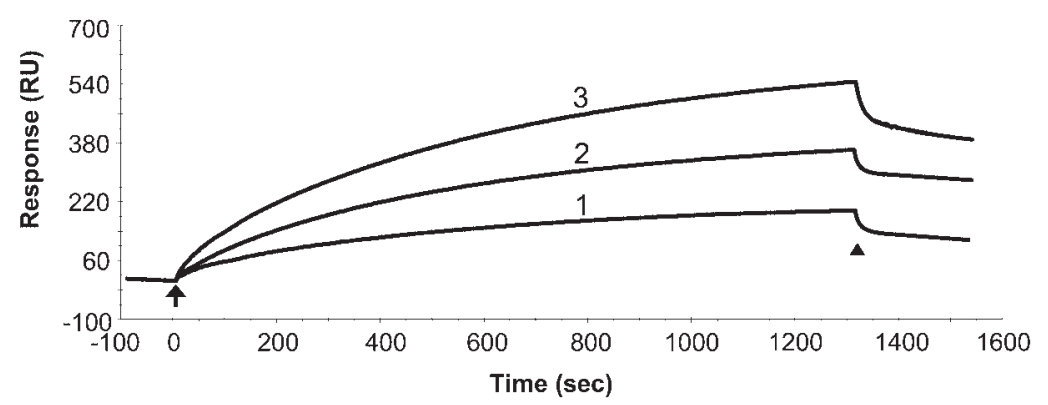

Fig. 6 Simultaneous Interaction of the Recombinant Inhibitors with Papain and MMP-2 Tested by Surface Plasmon Resonance. Approximately 2000 response units (RU) of papain were bound to a CM- 5 chip inserted in the BIAcore 2000 system. Then, N-hTIMP-1chCys-uPA ${ }_{19-31}, \mathrm{~N}-\mathrm{hTIMP}-1$-chCysWT, or chCysWT were injected for binding to papain. (A) Binding of N-hTIMP-1-chCys-uPA ${ }_{19-31}$ to papain (arrow: start of injection, arrowhead: end of injection). Both, the rise and drop off of the reference unit signal is mainly due to the change of buffer (bulk effect), whereas the difference in response (RU) before and after injection reflects the bound portion of chicken cystatin variant to immobilized papain. The very slow dissociation is due to the tight interaction with a $K_{\mathrm{i}}$ value of about $2 \mathrm{pm}$ (see Table 1) and a low dissociation rate constant, $k_{\text {off }}=3.5 \times 10^{-5} \mathrm{~s}^{-1}$, determined with the fluorogenic substrate Z-Phe-Arg-AMC from presteadystate analysis (Machleidt et al., 1993). (B) Addition of activated MMP-2 to the papain-multifunctional inhibitor complexes results in binding to N-hTIMP-1-chCys-uPA 19 - 31 (curve 3) and to N-hTIMP-1-chCysWT (curve 2), but not to chCysWT (curve 1); buffer bulk is not subtracted. (C) Injection of different concentrations of activated MMP-2 (51, 68, and $102 \mu \mathrm{g} / \mathrm{ml}$, curves 1-3, respectively) to the papain-N-hTIMP-1-chCys-uPA ${ }_{19-31}$ complex; sensorgrams after subtraction of buffer bulk. Using these binding curves, the binding constant for MMP-2 binding to the recombinant inhibitor was calculated.

\section{Expression of Multifunctional Inhibitors in Ovarian Cancer OV-MZ-6\#8 Cells}

Ovarian cancer OV-MZ-6\#8 cell lines were generated which express and secrete the novel bi- and trifunctional inhibitors. For this, the cells were stably transfected with pRc-RSV-derived expression plasmids encoding either pre-N-hTIMP-1-chCysWT, pre-N-hTIMP-1-chCysUPA $_{19-31}$, pre-N-hTIMP-3-chCysWT, or pre-N-hTIMP-3chCys-uPA $A_{19-31}$. To prove synthesis and secretion of the recombinant proteins, a sensitive ELISA (concentration range: 0.25 to $32 \mathrm{ng} / \mathrm{ml}$ ) was developed, which employs a polyclonal antibody against recombinant chCysWT as the catching antibody and a peroxidase-coupled monoclonal antibody directed against a $\mathrm{His}_{6}$-epitope as the detection antibody (data not shown). All stably transfected cell lines produced and secreted detectable amounts of the respective multifunctional inhibitor into the medium, with amounts ranging from 3 to $12 \mathrm{ng} / \mathrm{ml}$ secreted into the medium after growth for $48 \mathrm{~h}$. No reaction above the ELISA background (medium only) was observed by testing the conditioned medium of vector-transfected cells (data not shown). 


\section{Biological Activity of Multifunctional Inhibitors in Invasion Assays}

To analyze the effects of the recombinantly expressed multifunctional inhibitors on the invasive capacity of human ovarian cancer cells, we performed in vitro Matrigel invasion assays. Stably transfected cells were placed into the upper compartment of an invasion chamber on top of a Matrigel-coated filter, the lower compartment was filled with fetal calf serum (FCS)-containing medium as a chemoattractant. After $48 \mathrm{~h}$, the cells on the lower side of the filter were counted. The results given in Figure 7A demonstrate that the inhibitor-producing cells exhibit a significant decrease in invasion through Matrigel in comparison to the vector-transfected control cells. A direct quantitative comparison of the effectiveness of the different inhibitors expressed by the ovarian cancer cells is impossible, since (i) the cell clones produce varying amounts of the recombinant inhibitors and (ii) the portion of active recombinant protein is not known. In another set of experiments, purified and refolded recombinant N-hTIMP-1-chCysWT and N-hTIMP-1-chCys-uPA ${ }_{19-31}$, produced in $E$. coli, were added exogenously to wild-type OV-MZ-6\#8 cells. Again, the inhibitors inhibited invasion of the cancer cells through the Matrigel-coated filter (Figure 7B). In these experiments, N-hTIMP-1-chCys$\mathrm{uPA}_{19-31}$ reduced tumor cell migration to a lower extent than the bifunctional hybrid N-hTIMP-1-chCysWT, very likely due to the fact that the active concentration of the chCysWT-harboring fusion protein was much higher as compared to the chCys-uPA $19-31$ variant (approx. 8\% versus approx. 4\%).

A

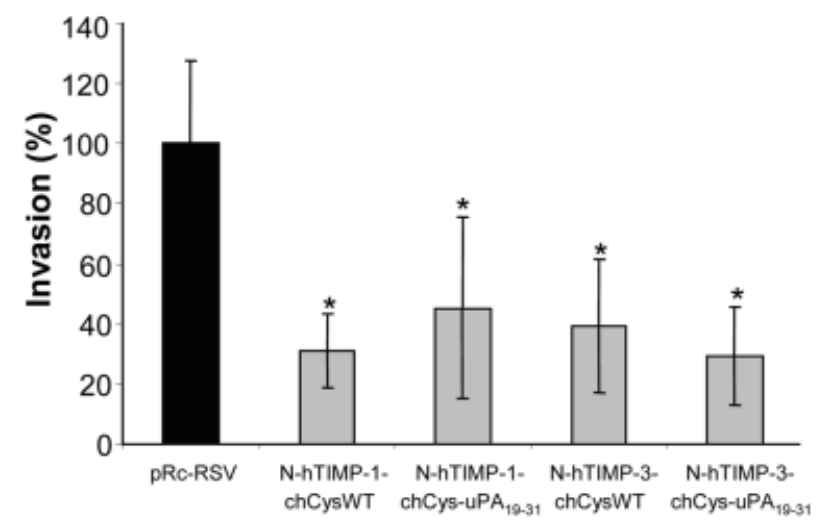

B

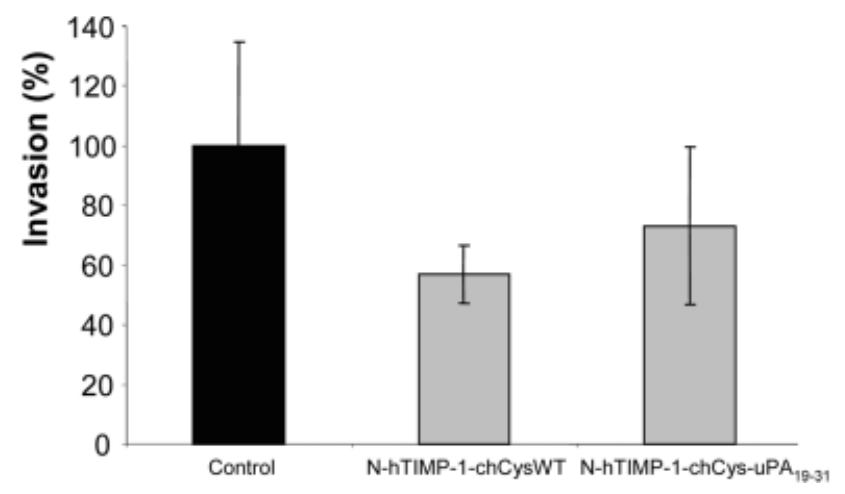

Fig. 7 In vitro Matrigel Invasion Assays.

(A) Stably transfected ovarian cancer OV-MZ-6\# 8 cells were placed into the upper compartments of the invasion chambers $\left(5 \times 10^{4}\right.$ cells in $500 \mu \mathrm{l} 0.1 \% \mathrm{BSA} / \mathrm{DMEM}$ per insert). The lower chambers of the inserts were filled with $750 \mu \mathrm{l}$ DMEM containing $10 \%$ FCS as the chemoattractant. After $48 \mathrm{~h}$ incubation, the Matrigel layer plus noninvaded cells of the upper compartment was wiped off, the invaded cells on the lower side of the filter were fixed, stained, and counted. Assays were performed in triplicate. Statistical differences relative to the control pRc-RSV cells are denoted as $\left(^{*}\right), p<0.001$ (Mann-Whitney U-test). (B) Invasion assays with recombinant purified and refolded inhibitors isolated from E. coli. Wild-type OV-MZ-6\# 8 cells $\left(5 \times 10^{4}\right.$ cells in $\left.400 \mu \mathrm{l}\right)$ were applied to each upper compartment and recombinant inhibitors (approx. $50 \mu \mathrm{g}$ protein in $150 \mu \mathrm{l}$ DMEM) were added to the cells together with $500 \mu \mathrm{g}$ BSA. The controls received PBS with $500 \mu \mathrm{g} \mathrm{BSA}$. The diagram depicts results of one representative experiment performed in triplicate. 


\section{Discussion}

An important step in tumor invasion and metastasis is the degradation of extracellular matrix, allowing cells to migrate through connective tissue and basement membranes. These processes involve the action and interaction of several different proteolytic systems such as cysteine proteases, serine proteases, and MMPs. In vivo, all of these protease systems are controlled by specific natural inhibitors, e.g. MMPs by the TIMP-family and extracellular cysteine proteases by cystatin $\mathrm{C}$ (for reviews see Kos and Lah, 1998; Andreasen et al., 2000; Johansson et al., 2000; Stamenkovic, 2000; Ellis and Murphy, 2001; Magdolen et al., 2002). Due to the essential role of proteolytic systems in tumor invasion and metastasis, synthetic inhibitors were developed to be used as therapeutic agents to affect tumor progression (Sperl et al., 2001; Coussens et al. , 2002). All of these natural and synthetic inhibitors are directed against only one of the mentioned protease systems. Thus, a promising strategy in tumor therapy is to apply multifunctional inhibitors, which reduce the activity of several or all of these protease systems involved in tumor progression.

Based on this idea a novel bifunctional inhibitor chCysuPA $_{19-31}$ was developed by us (Muehlenweg et al., 2000) which reduces the activity of cysteine proteases, such as cathepsin B and L, and simultaneously also prevents binding of UPA to its receptor UPAR. In this study we have extended this strategy and have described the design and generation of additional multifunctional inhibitors, N-hTIMP-1-chCysWT, N-hTIMP-1-chCys-uPA ${ }_{19-31}$, NhTIMP-3-chCysWT, and N-hTIMP-3-chCys-uPA 19-31, , which interfere with the MMP and cysteine protease system, and in the case of $\mathrm{UPA}_{19-31}$-containing inhibitors also with the UPA system. These recombinant bi- and trifunctional inhibitors were expressed in E. coli and purified in an active conformation. In preparations of fusion proteins harboring the chCys-uPA $\mathrm{A}_{19-31}$-moiety, generally, a smaller amount of active protein was present compared to chCysWT-containing molecules, probably due to a less effective refolding of the active, native structure. Therefore, cloning and expression of the trifunctional inhibitor N-hTIMP-1-chCys-uPA 19-31 $_{1}$ was additionally performed under native conditions in the eukaryotic baculovirus expression system. In fact, using this approach, higher amounts of this inhibitor in active form was isolated using the baculovirus system as compared to the $E$. coli system. This variant displays a slightly elevated apparent molecular mass most probably due to glycosylation of the TIMP-1 moiety (Brew et al., 2000).

Quantitative evaluation of the inhibitory capacities of the recombinant inhibitors demonstrated that the individual inhibitory domains are similarly potent as their natural counterparts: (i) the $K_{\mathrm{i}}$ values $(1.4 \mathrm{pM}-2 \mathrm{pM})$ of the inhibitors against the cysteine protease papain are very close to the inhibition constant (1.4 pM) of natural wildtype cystatin (Machleidt et al., 1993). (ii) The binding affinity of the TIMP-variants to MMP-2 as tested by SPR $\left(K_{d}\right.$ of about $30 \mathrm{nM}$ ) is also similar to that of TIMP-1 with MMP-2 (Olson et al., 1997). (iii) The binding affinity of $\mathrm{UPA}_{19-31^{-}}$ containing cystatin variants toward UPAR is in the range of uPA binding to uPAR when analyzed by SPR ( 5 nM versus $17 \mathrm{~nm}$; Muehlenweg et al., 2000). These results strongly indicate that in the bi- and trifunctional inhibitors the functional integrity of each individual module is not significantly affected when recombinantly fused together. Thus, these multifunctional inhibitors may represent suitable tools to efficiently inhibit members of either of the three targeted protease families.

We have previously demonstrated that the bifunctional inhibitor chCys-uPA ${ }_{19-31}$ inhibits cysteine proteases and at the same time interferes with UPA/uPAR-interaction (Muehlenweg et al., 2000). The same is true for the novel bi- and trifunctional inhibitors with respect to interaction with cysteine proteases and MMPs as shown by surface plasmon resonance technology. Although the multifunctional inhibitors have the capacity to simultaneously inhibit more than one of their target molecules, it is not imperative that a single trifunctional inhibitor can inhibit all three target molecules at the same time. Rather, it is only important that each molecule carries the potential to inhibit one of the three systems. The functions of the various proteolytic systems may overlap or even be redundant, as indicated by the apparent phenotype of knockout mice deleted for these proteolytic factors (Carmeliet and Collen, 1998). Therefore, the application of multifunctional inhibitors is expected to be more efficient as compared to therapeutic molecules with inhibitory activity against a single system only.

The analyses of the inhibitory capacity of the multifunctional inhibitors in in vitro invasion assays, both by use of transfected cancer cells endogenously producing and releasing the inhibitors and by exogenous addition of the recombinant proteins, demonstrated that the inhibitors do considerably reduce invasion of ovarian cancer cells. The characterization of recombinant purified inhibitors, although clearly demonstrating their inhibitory activity, was hampered by the fact that a high percentage of the purified proteins was inactive (in most cases due to misfolding by the refolding procedure after expression in E. coli, which was only partially improved by soluble expression with the baculovirus system). Therefore, the approach of exogenously applying recombinantly produced, purified inhibitors as therapeutic molecules in cancer treatment seems to be rather unattractive. However, the endogenous (relatively low) expression of the inhibitors by transfected ovarian cancer cells showed a dramatic effect on in vitro invasion, indicating that a therapeutic approach employing e.g. viral vectors or other gene transfer systems may be feasible to affect tumor cell invasion. The very small size of our compact therapeutic molecules carrying up to three different inhibitory functions may prove beneficial for generating appropriate vectors, especially, if e.g. cell type-specific expression is aspired, where rather large regulatory promoter sequences are used. Finally, one has also to consider that 
the introduction of any new inhibitory agent in cancer therapy may be easier to achieve with only one therapeutic molecule carrying multiple functions than with e.g. three individual inhibitors.

In summary, the functional characterization of the multifunctional proteins presented here provides the basis for analyses of the inhibitory capacities of the bi- and trifunctional inhibitors in vivo. In fact, in a recent study the effects on tumor growth and spread of ovarian cancer cells in nude mice endogenously expressing the inhibitors versus vector controls were analyzed (Krol et al., 2003). The recombinant proteins could be detected in ascitic fluid and in tumor tissue indicating stable production of the therapeutic molecules. Most importantly, in the case of inhibitor-producing cell lines, a distinct reduction of the tumor mass was observed, which demonstrates sufficient concentrations of the inhibitors over time to achieve a therapeutic effect. Thus, these novel bi- and trifunctional inhibitors represent candidates for the exploration of new therapeutic approaches in cancer patients, e.g. via delivery of the genes encoding the therapeutic molecules by viral or nonviral vector systems (Monahan and Samulski, 2000; Scherer et al., 2002).

\section{Materials and Methods}

\section{Generation of Expression Vectors Encoding Bi- and Trifunctional Inhibitors}

The cDNAs encoding human TIMP-1, human TIMP-3 (both kindly provided by A. Krüger, Institut für Experimentelle Onkologie und Therapieforschung, TU München, Germany), as well as chicken cystatin (chCysWT; Muehlenweg et al., 2000) were used as templates for multiple PCR amplification steps to generate genes encoding bifunctional inhibitors. For synthesis of genes encoding trifunctional inhibitors, the cDNA encoding chCysuPA $_{19-31}$ was used, a cystatin variant, that harbors the UPARbinding site of the uPA molecule (Muehlenweg et al., 2000).

The coding regions of the N-terminal domains of TIMP-1 [amino acids (aa) 1-128] and TIMP-3 (aa 1-123) were fused to the coding regions of chCysWT (aa 1-115) and of chCys$\mathrm{uPA}_{19-31}$ consisting of 117 aa. Between the two inhibitor domains, a stretch of 10 aa was introduced as a flexible linker. The constructs were inserted into the multiple cloning site of the $E$. coli expression vector pQE-60 (Qiagen, Hilden, Germany) which provides a $\mathrm{C}$-terminal $\mathrm{His}_{6}$-tag. The recombinant plasmids were transformed into cells of the $E$. coli strain M15 (pREP4).

For generation of eukaryotic expression plasmids, again a two-step cloning strategy was applied: (i) the PQE-60-derived plasmids encoding the various bi- and trifunctional inhibitors were used as templates for PCR amplification of the cystatin-encoding part including the $\mathrm{N}$-terminally located flexible linker and the $\mathrm{C}$-terminal $\mathrm{His}_{6}$-tag. These fragments were directionally subcloned into the eukaryotic expression vector pRc-RSV. (ii) The coding regions of the $\mathrm{N}$-terminal domains of TIMP-1 (aa 1-128) plus its $\mathrm{N}$-terminally located signal sequence consisting of 23 aa and TIMP-3 (aa 1-123) plus its native signal sequence (23 aa), respectively, were amplified and inserted 5 ' of the cystatin variant-encoding sequences. The deduced aa sequences of the mature recombinant fusion proteins (expressed by eukaryotic cells) are identical to those of the proteins expressed in $E$. coli. For expression in insect cells, the synthetic gene encoding
preN-hTIMP-1-chCys-uPA ${ }_{19-31}$ was ligated into the Hindlll sites of the transfer vector $\mathrm{pBac} 2 \mathrm{x}$ (modified $\mathrm{pBac} 4 \mathrm{x}-1$, Novagen; $\mathrm{P}$. Rettenberger, unpublished), downstream of the polyhedrin promoter.

In all cases, in the expression vectors the correct orientation and sequence of the cloned DNA was verified by sequencing (TopLab, Martinsried, Germany).

\section{Bacterial Expression, Purification and Refolding of Multifunctional Inhibitors}

E. coli clones were grown in LB Medium supplemented with $100 \mu \mathrm{g} / \mathrm{ml}$ ampicillin and $25 \mu \mathrm{g} / \mathrm{ml}$ kanamycin until an $\mathrm{OD}_{600}$ of $0.8-0.9$, and subsequently expression of the recombinant protein was induced for $5 \mathrm{~h}$ by addition of isopropyl-B-D-thiogalactopyranoside (IPTG; final concentration $2 \mathrm{~mm}$ ). Purification of the proteins was performed under denaturing and slightly reducing conditions. The bacterial cells were harvested by centrifugation and then lysed in $6 \mathrm{~m}$ guanidine hydrochloride (GuHCl), $100 \mathrm{~mm}$ $\mathrm{NaH}_{2} \mathrm{PO}_{4}, 10 \mathrm{~mm}$ Tris-HCl, pH 8.0, $8 \mathrm{~mm} \beta$-mercaptoethanol by gently shaking for $2 \mathrm{~h}$ at room temperature (RT). The cell debris was removed by centrifugation and the supernatant subjected to $\mathrm{Ni}^{2+}$-nitrilotriacetic acid (NTA)-agarose affinity chromatography. After four washing steps, first with $6 \mathrm{M} \mathrm{GuHCl}, 100 \mathrm{~mm}$ $\mathrm{NaH}_{2} \mathrm{PO}_{4}, 8 \mathrm{~mm} \beta$-mercaptoethanol, $10 \mathrm{~mm}$ Tris- $\mathrm{HCl}, \mathrm{pH} 8.0$ and,

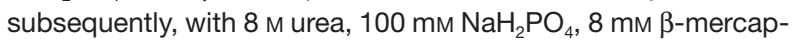
toethanol, $100 \mathrm{~mm}$ Tris- $\mathrm{HCl}(\mathrm{pH} 8.0, \mathrm{pH} 7.0$, and pH 6.3, respectively), the proteins were eluted with this buffer but at $\mathrm{pH} 4.1$. For refolding of N-hTIMP-1-chCysWT and N-hTIMP-1-chCys$\mathrm{uPA}_{19-31}$, dithiothreitol (DTT) was added at a final concentration of $50 \mathrm{~mm}$ and the proteins were dialyzed against $6 \mathrm{~m}$ urea, $0.02 \%$ $\mathrm{NaN}_{3}, 50 \mathrm{~mm}$ Tris- $\mathrm{HCl}, \mathrm{pH} 8.0$, for $8 \mathrm{~h}$ at RT, followed by two dialysis steps at $4^{\circ} \mathrm{C}$ each for $48 \mathrm{~h}$ against $2 \mathrm{~m}$ urea, $300 \mathrm{~mm} \mathrm{NaCl}$, $2.5 \mathrm{~mm}$ reduced glutathione, $0.5 \mathrm{~mm}$ oxidized glutathione, $0.02 \% \mathrm{NaN}_{3}, 50 \mathrm{~mm}$ Tris- $\mathrm{HCl}, \mathrm{pH} 8.0$, and one dialysis step against phosphate buffered saline (PBS), $\mathrm{pH} 7.4$, for 24 h. For refolding of N-hTIMP-3-chCysWT and N-hTIMP-3-chCys$\mathrm{uPA}_{19-31}$, a modification of the method described by Negro et al. (1997) was used. Briefly, $2 \mathrm{ml}$ of $\mathrm{Ni}^{2+-N T A}$ resin and $\beta$-mercaptoethanol to a final concentration of $8 \mathrm{~mm}$ were added to $1 \mathrm{mg}$ of eluted protein. The protein solution was gently shaken for $2 \mathrm{~h}$ at RT and then dialyzed against $100 \mathrm{~mm}$ sodium phosphate, $\mathrm{pH} 8.3$, for $3 \mathrm{~d}$ at $4^{\circ} \mathrm{C}$. The refolded protein was eluted from the resin with $8 \mathrm{~m}$ urea, $100 \mathrm{~mm} \mathrm{NaH} \mathrm{PO}_{4}, 10 \mathrm{~mm}$ Tris-HCl, pH 4.1, and then dialyzed against PBS, $\mathrm{pH} 7.4$, for $24 \mathrm{~h}$. Refolded proteins were stored in aliquots at $-20^{\circ} \mathrm{C}$ until use.

\section{Production of the Trifunctional Inhibitor N-hTIMP-1-chCys-uPA ${ }_{19-31}$ in Insect Cells}

Spodoptera frugiperda Sf21 cells were routinely maintained in TC100 medium (Gibco, Pailsley, UK) supplemented with 10\% foetal calf serum (FCS) and Sf9 cells in Sf900ll serum-free medium (Gibco) at $28^{\circ} \mathrm{C}$. BacPAK6 $\Delta$ chi (L. A. King, unpublished), a mutant of the autographa californica multiple nucleopolyhedrovirus (AcMNPV) variant BacPAK6 (Kitts and Possee, 1993) lacking the chitinase gene (Thomas et al., 1998; Possee et al., 1999) was used as baculovirus vector.

Cotransfection was performed essentially as previously described (King and Possee, 1992). Briefly, adherend Sf21 were incubated with a mixture of Bsu36l-digested BacPAK6 $\Delta$ chi, transfer vector pBac2x-preN-hTIMP-1-chCys-uPA ${ }_{19-31}$, and Lipofectin $^{\text {TM }}$ (Gibco) in serum-free TC100. After overnight incubation, the medium was replaced with TC100 supplemented with $10 \%$ FCS and harvested after $3 \mathrm{~d}$ of further incubation. To identify recombinant virus the cell supernatant was screened in a plaque assay with lac $Z$ as genetic marker for the wild-type 
virus vector (Kitts and Possee, 1993). The amplification of recombinant virus was performed in suspension cultures of Sf9 cells as previously described (King and Possee, 1992).

For protein production, suspension cultures of $2 \times 10^{6} \mathrm{Sf9}$ cells $/ \mathrm{ml}$ were infected at a multiplicity of infection (m.o.i.) of 2 or mock-infected, and harvested after $48 \mathrm{~h}$ post-infection. The cell supernatant was collected after centrifugation at $1000 \mathrm{~g}$ for $10 \mathrm{~min}$ at $4^{\circ} \mathrm{C}$, and then analysed by Western blot using INDIA ${ }^{\mathrm{TM}}$ HisProbe-HRP (Pierce, Tattenhall, UK) to detect the recombinant hexahistidine-tagged protein. The supernatant was subjected to $\mathrm{Ni}^{2+-}$-affinity chromatography (Chelating Sepharose; Amersham Pharmacia Biotech, Little Chalford, UK). After the column was washed three times with $50 \mathrm{~mm}$ imidazole, $500 \mathrm{~mm} \mathrm{NaCl}, \mathrm{pH}$ 7.0, at $4{ }^{\circ} \mathrm{C}$, the recombinant protein was eluted with $450 \mathrm{~mm}$ imidazole, $500 \mathrm{~mm} \mathrm{NaCl}, \mathrm{pH} 7.0$, at $4^{\circ} \mathrm{C}$. Peak fractions were pooled and dialyzed against PBS, $\mathrm{pH} 7.4$, for $24 \mathrm{~h}$. The purity of the eluted recombinant protein was assessed by SDS polyacrylamide gel electrophoresis followed by Coomassie Blue staining and the concentration determined using the Bradford protein assay (Bio-Rad, Hemel Hempstead, UK) and then stored at $-20^{\circ} \mathrm{C}$ until use.

\section{Stable Transfection of OV-MZ-6\#8 Cells}

OV-MZ-6\#8 cells (Fischer et al., 1998; Lutz et al., 2001) were transfected in the presence of Lipofectin ${ }^{\mathrm{TM}}$ (Gibco, Karlsruhe, Germany) with the various eukaryotic expression plasmids (pRc-RSV-N-hTIMP-1-chCysWT; pRc-RSV-N-hTIMP-1-chCysuPA $_{19-31}$; pRc-RSV-N-hTIMP-3-chCysWT; pRc-RSV-N-hTIMP3-chCys-uPA 19-31 $\left._{1}\right)$ and stably transfected cells were isolated upon G418 (geneticin) selection. Transfections with the empty vector pRc-RSV served as a control.

For detection and quantification of the recombinant multifunctional inhibitors, a sandwich ELISA format was developed in a similar fashion as described previously (Kotzsch et al., 2000). For this, rabbit polyclonal antibodies directed against purified recombinant chCysWT produced in E. coli (Muehlenweg et al., 2000) were generated (Pineda Antikörperservice, Berlin, Germany) and used as the catcher antibody. As the detecting antibody, a mouse monoclonal antibody directed to the histidine-tag (Penta-His) coupled to peroxidase (Qiagen) was applied. Serial dilutions of recombinant chCysWT in sample buffer, covering a concentration range of 0.25 to $32 \mathrm{ng} / \mathrm{ml}$, served as standard.

\section{MMP Activity Assays}

The inhibitory activity of the recombinant bi- or trifunctional inhibitors was tested in MMP-1, -2 , and -9 activity assays (Biotrak $^{\mathrm{TM}}$; Amersham Biosciences, Freiburg, Germany). The assay buffer contained $50 \mathrm{~mm}$ Tris- $\mathrm{HCl}, \mathrm{pH} 7.6,1.5 \mathrm{~mm} \mathrm{NaCl}, 0.5 \mathrm{~mm}$ $\mathrm{CaCl}_{2}, 1 \mu \mathrm{M} \mathrm{ZnCl}_{2}, 0.01 \%$ (v/v) Brij ${ }^{\mathrm{TM}} 35,0.01 \%(\mathrm{w} / \mathrm{v})$ gelatin (only in the MMP-2 assay) and $500 \mu \mathrm{g} / \mathrm{ml}$ of bovine serum albumin (BSA). Fifty $\mu \mathrm{l}$ of enzyme (MMP-2: $6 \mathrm{ng} / \mathrm{ml}$; MMP-1: $25 \mathrm{ng} / \mathrm{ml}$; MMP-9: $8 \mathrm{ng} / \mathrm{ml}$ ) were activated with $50 \mu \mathrm{l}$ of $0.5 \mathrm{~mm}$ $p$-aminophenylmercuric acetate (APMA) for $15 \mathrm{~min}$ at $37{ }^{\circ} \mathrm{C}$. Then, inhibitors $(0.5-2 \mu \mathrm{g}$ in 10 to $40 \mu \mathrm{l})$ were added and incubated for 20 min at RT, and, finally, the microtiter plate of the various MMP-assays was incubated overnight at $4^{\circ} \mathrm{C}$. As negative control, a mixture without MMPs was used; as a positive controls, MMPs were incubated with PBS instead of inhibitors, or heat-denatured $\left(10 \mathrm{~min}\right.$ at $\left.95^{\circ} \mathrm{C}\right)$ inhibitors were used.

The next day, the plates were washed four times ( $10 \mathrm{~mm}$ sodium phosphate, $\mathrm{pH} 7.0,0.05 \%$ Tween 20 ). One hundred $\mu \mathrm{l}$ of detection reagent (consisting of detection enzyme and chromogenic substrate) were added to each well and the resulting color changes at $405 \mathrm{~nm}$ were monitored over several hours in a spectrophotometer.

\section{Reverse Zymographic Analyses}

The inhibitory activity of recombinant trifunctional inhibitors against the cysteine protease papain was tested by reverse zymography. A $15 \%$ SDS polyacrylamide minigel containing $0.1 \%$ $(\mathrm{w} / \mathrm{v})$ casein and a control gel without casein were prepared. The inhibitor samples (approx. $0.25 \mu \mathrm{g}$ ) were loaded in nonreducing sample buffer into the wells of these gels and electrophoresis was performed. After electrophoresis, gels were washed in $2.5 \%$ Triton X-100 three times for $30 \mathrm{~min}$ at RT and then incubated in $100 \mathrm{~mm}$ phosphate buffer, $\mathrm{pH} 6.0$, containing $2 \mathrm{~mm}$ cysteine, $1 \mathrm{~mm}$ EDTA, and $0.01 \mathrm{mg} / \mathrm{ml}$ papain $\left(40^{\circ} \mathrm{C}\right.$ for $\left.2.5 \mathrm{~h}\right)$. Thereafter the gels were stained with $0.05 \%$ Coomassie Brilliant Blue in $40 \%$ ethanol $/ 10 \%$ acetic acid solution overnight and destained in $35 \%$ ethanol $/ 10 \%$ acetic acid for $3 \mathrm{~h}$.

The inhibitory activity of recombinant bi- and trifunctional inhibitors against MMP-2 was also tested by reverse zymography. Minigels were prepared containing $12.5 \%$ SDS polyacrylamide, $1 \mathrm{mg} / \mathrm{ml}$ gelatin, $0.5 \mu \mathrm{g} / \mathrm{ml}$ MMP-2 (Roche, Penzberg, Germany). The inhibitor samples (approx. $0.25 \mu \mathrm{g}$ ) each in nonreducing sample buffer were loaded and electrophoresis was performed with $15 \mathrm{~mA}$ at $4{ }^{\circ} \mathrm{C}$. After electrophoresis, the gels were washed in $50 \mathrm{~mm}$ Tris- $\mathrm{HCl}, \mathrm{pH} 7.5,5 \mathrm{~mm} \mathrm{CaCl}_{2}, 5 \mu \mathrm{M} \mathrm{ZnCl}, 2.5 \%$ Triton $\mathrm{X}-100\left(3 \mathrm{~h}, 37^{\circ} \mathrm{C}\right)$ with three buffer changes. Incubation was performed in $50 \mathrm{mM}$ Tris/ $\mathrm{HCl}, \mathrm{pH} 7.5,5 \mathrm{mM} \mathrm{CaCl}_{2}, 5 \mu \mathrm{M} \mathrm{ZnCl}$, $0.02 \% \mathrm{NaN}_{3}$ at $37^{\circ} \mathrm{C}$ overnight. After fixation in $40 \%$ ethanol/10\% acetic acid for $10 \mathrm{~min}$, the gels were stained with $0.5 \%$ Coomassie Blue in $35 \%$ ethanol $/ 10 \%$ acetic acid for at least $2 \mathrm{~h}$ and destained in $35 \%$ ethanol$/ 10 \%$ acetic acid. A control gel without gelatin and without MMP-2 was run and stained as well.

\section{Determination of Kinetic Constants and Active Concentrations}

To determine the inhibitory activity of the multifunctional inhibitors toward cysteine proteases continuous fluorimetric inhibition assays were performed and evaluated as described previously (Muehlenweg et al., 2000).

\section{Flow Cytofluorometry}

U937 cells were stimulated with $1 \mathrm{~mm}$ (final concentration) of phorbol-12-myristate-13-acetate-4-O-methyl ether (SigmaAldrich, Taufkirchen, Germany) for $72 \mathrm{~h}$ at $37^{\circ} \mathrm{C}$. After washing with PBS, the cells were incubated with $50 \mathrm{~mm}$ glycine $/ 100 \mathrm{~mm}$ $\mathrm{NaCl}, \mathrm{pH} 3.0$, for $1 \mathrm{~min}$ at $\mathrm{RT}$ to dissociate endogenous receptorbound UPA and then the acidic buffer was neutralized with an equal volume of $500 \mathrm{~mm}$ HEPES/100 mM NaOH, pH 7.5. After washing, the cells were resuspended in PBS/0.1\% BSA $\left(10^{7}\right.$ cells $/ \mathrm{ml}$ ) and then $2.5 \times 10^{5}$ cells were incubated for $30 \mathrm{~min}$ with a mixture of fluorescein isothiocyanate (FITC)-labeled high molecular weight (HMW) UPA (16 ng) plus different concentrations of refolded multifunctional inhibitors or the amino terminal fragment of UPA (ATF). Cell-associated fluorescence was determined by flow cytofluorometry (Muehlenweg et al., 2000).

\section{Surface Plasmon Resonance Analysis}

Simultaneous interaction of the recombinant inhibitor proteins with the cysteine protease papain and MMP-2 was followed by real time analysis utilizing the BIAcore 2000 system (BIAcore AB, Uppsala, Sweden). All experiments were performed at $25^{\circ} \mathrm{C}$ at a flow rate of $5 \mu \mathrm{l} / \mathrm{min}$. Papain was immobilized to a CM- 5 chip using the amino-coupling kit according to the manufacturer's recommendation. Then, $200 \mu \mathrm{l}$ of N-hTIMP-1-chCysWT or NhTIMP-1-chCys-uPA ${ }_{19-31}$ or chCysWT (final concentration $50 \mu \mathrm{g} / \mathrm{ml}$ ) in HBS-P-BSA buffer [10 mm HEPES, pH 7.4, $150 \mathrm{~mm}$ 
$\mathrm{NaCl}, 0.005 \%(\mathrm{v} / \mathrm{v})$ Tween 20, 0.05\% BSA] were applied to the papain-coupled chip to form a papain-cystatin complex. After intensive washing, $110 \mu \mathrm{l}$ of different concentrations $(51,68$, and $102 \mu \mathrm{g} / \mathrm{ml}$ ) of MMP-2 (Roche), activated by $p$-aminophenylmercuric acetate (APMA) $\left(30 \mathrm{~min}\right.$ at $\left.37^{\circ} \mathrm{C}\right)$, were injected to follow the formation of the ternary papain-[N-hTIMP-1-cystatin(variant)]-MMP-2 complex. Regeneration was achieved by injection of HBS-EP puffer [10 mm HEPES, pH 7.4, $150 \mathrm{~mm} \mathrm{NaCl}, 0.005 \%$ ( $\mathrm{v} / \mathrm{v})$ Tween 20, $3 \mathrm{~mm}$ EDTA]. The association and dissociation constants of the interaction of MMP-2 with the N-hTIMP-1chCys-uPA ${ }_{19-31}$ and N-hTIMP-1-chCysWT were determined using the BIA evaluation software of BIAcore.

\section{Cell Invasion Assays}

Invasion assays were performed according to Szpaderska and Frankfater (2001). Aliquots of Matrigel $(11.3 \mathrm{mg} / \mathrm{ml}$, Becton Dickinson Labware, Bedford, USA) were stored frozen at $-20^{\circ} \mathrm{C}$. After thawing on ice overnight the Matrigel was diluted 1:24 with cold PBS and the membrane inserts $(6.4 \mathrm{~mm}$ diameter, $8 \mu \mathrm{m}$ pores; Becton Dickinson Labware) for 24-well plates were coated with $60 \mu \mathrm{l}$ Matrigel per insert (density of $85 \mu \mathrm{g} / \mathrm{cm}^{2}$ ). The plates were incubated for $3 \mathrm{~h}$ at $37^{\circ} \mathrm{C}$ in a cell culture incubator. After gelling the Matrigel was dried overnight in uncovered plates in a laminar hood. The next day, the gel was rehydrated for $2 \mathrm{~h}$ by addition of $200 \mu \mathrm{l}$ serum-free Dulbecco's Modified Eagle Medium (DMEM)/0.1\% BSA. Transfected cells were grown until 60 to $80 \%$ confluence was reached and adjusted to $10^{5} \mathrm{cells} / \mathrm{ml}$ DMEM/0.1\% BSA. $5 \times 10^{4}$ transfected cells/500 $\mu$ l medium were seeded into each insert. The lower chambers of the inserts were filled with $750 \mu \mathrm{l}$ DMEM containing $10 \%$ FCS as a chemoattractant. For every value, assays were performed in triplicate. After $48 \mathrm{~h}$ of incubation the Matrigel with the noninvaded cells was wiped off with a tissue and invaded cells on the lower side of the filter were fixed and stained (Diff-Quick ${ }^{\circledR}$, Dade Behring AG, Switzerland). The stained cells were counted under the microscope (100× magnification) with the help of a grid.

Cell invasion assays with recombinant inhibitors isolated from E. coli or the baculovirus system were performed similarly. Wildtype OV-MZ-6\# 8 cells $\left(5 \times 10^{4}\right.$ cells) in $400 \mu$ I DMEM were applied to each insert and recombinant inhibitors (up to $50 \mu \mathrm{g}$ inhibitor protein in $150 \mu \mathrm{l}$ ) were added to the cells together with $500 \mu \mathrm{g}$ BSA. Controls received PBS with $500 \mu \mathrm{g}$ BSA. As another control, heat-denatured inhibitors $\left(10 \mathrm{~min}\right.$ at $\left.95^{\circ} \mathrm{C}\right)$ were used. The invasion was stopped after $24 \mathrm{~h}$ of incubation and the level of cell invasion was detected as described above.

\section{Acknowledgments}

The excellent technical assistance of S. Creutzburg, C. Schnelldorfer and R. Zauner is gratefully acknowledged. We thank L. A. King (Oxford Brookes University, UK) for providing the baculovirus vector BacPAK6 $\Delta$ chi, S. Mann (Oxford Brookes University, UK) for her help with the insect cell cultures, and T. Langerholc (University of Ljubljana, Slowenia; supported by a Madame Curie Training Site grant) for his help with protein expression in $E$. coli. Initial BIAcore analyses were performed in the laboratory of E.-K. Sinner (MPI für Biochemie, Martinsried). We also thank W. Machleidt (Ludwig-Maximilians-Universität, München), T. Luther (Technical University Dresden) and B. Muehlenweg (Wilex AG, Munich) for helpful discussions. Part of this work was supported by grants of the Sonderforschungsbereich 469 (A4, A8) and the Graduiertenkolleg 333 of the Deutsche Forschungsgemeinschaft (DFG).

\section{References}

Andreasen, P.A., Egelund, R., and Peterson, H.H. (2000). The plasminogen activation system in tumor growth, invasion and metastasis. Cell. Mol. Life Sci. 57, 25-40.

Andreasen, P.A., Kjøller, L., Christensen, L., and Duffy, M.J. (1997). The urokinase-type plasminogen activator system in cancer metastasis. Int. J. Cancer 72, 1-22.

Brew, K., Dinakarpandian, D., and Nagase, H. (2000). Tissue inhibitors of metalloproteinases: evolution, structure and function. Biochim. Biophys. Acta 1477, 267-283.

Carmeliet, P., and Collen, D. (1998). Development and disease in proteinase-deficient mice: role of the plasminogen, matrix metalloproteinase and coagulation system. Thromb. Res. 91, 255-285.

Coussens, L.M., Fingleton, B., and Matrisian, L.M. (2002). Matrix metalloproteinase inhibitors and cancer: trials and tribulations. Science 295, 2387-2390.

Curran, S., and Murray, G.I. (1999). Matrix metalloproteinases in tumor invasion and metastasis. J. Pathol. 189, 300-308.

Ellis, V., and Murphy, G. (2001). Cellular strategies for proteolytic targeting during migration and invasion. FEBS Lett. 506, 1-5.

Fischer, K., Lutz, V., Wilhelm, O., Schmitt, M., Graeff, H., Heiss, P., Nishiguchi, T., Harbeck, N., Kessler, H., Luther, T., Magdolen, V., and Reuning, U. (1998). Urokinase induces proliferation of human ovarian cancer cells: characterization of structural elements required for growth factor function. FEBS Lett. 438, 101-105.

Fong, S., Doyle, M.V., Goodson, R.J., Drummond, R.J., Stratton, J.R., McGuire, L., Doyle, L.V., Chapman, H.A., and Rosenberg, S. (2002). Random peptide bacteriophage display as a probe for urokinase receptor ligands. Biol. Chem. 383, $149-158$.

Johansson, N., Ahonen, M., and Kahari, N.M. (2000). Matrix metalloproteinases in tumor invasion. Cell. Mol. Life Sci. 57, 5-15.

King, L.A., and Possee, R.D. (1992). The Baculovirus Expression System. A Laboratory Guide (London, UK: Chapman and Hall).

Kitts, P.A., and Possee, R.D. (1993). A method for producing recombinant baculovirus expression vectors at high frequency. Biotechniques 14, 810-817.

Kos, J., and Lah, T. (1998). Cysteine proteinases and their endogenous inhibitors: target proteins for prognosis, diagnosis and therapy in cancer. Oncol. Rep. 5, 1349-1361.

Kotzsch, M., Luther, T., Harbeck, N., Ockert, D., Lutz, V., Noack, F., Grossmann, D., Albrecht, S., Kramer, M.D., Lossnitzer, A. et al. (2000). New ELISA for quantitation of human urokinase receptor (CD87) in cancer. Int. J. Oncol. 17, 827-834.

Krol, J., Kopitz, C., Kirschenhofer, A., Schmitt, M., Magdolen, U., Krüger, A., and Magdolen, V. (2003). Inhibition of intraperitoneal tumor growth of human ovarian cancer cells by bi- and trifunctional inhibitors of tumor-associated proteolytic systems. Biol. Chem. 384, 1097-1102.

Lah, T.T., and Kos, J. (1998). Cysteine proteinases in cancer progression and their clinical relevance for prognosis. Biol. Chem. 379, 125-130.

Lutz, V., Reuning, U., Krüger, A., Luther, T., von Steinburg, S.P., Graeff, H., Schmitt, M., Wilhelm, O.G., and Magdolen, V. (2001). High level synthesis of recombinant soluble urokinase receptor (CD87) by ovarian cancer cells reduces intraperitoneal tumor growth and spread in nude mice. Biol. Chem. 382, 789-798.

Machleidt, W., Assfalg-Machleidt, I., and Auerswald, E.A. (1993). Kinetics and molecular mechanism of inhibition of cysteine proteinases by their protein inhibitors. In: Innovations on Pro- 
teases and Their Inhibitors, F.X. Aviles, ed. (Berlin, Germany: Walter de Gruyter), pp. 179-196.

Magdolen, U., Krol, J., Sato, S., Mueller, M.M., Sperl, S., Krüger, A., Schmitt, M., and Magdolen, V. (2002). Natural inhibitors of tumor-associated proteases. Radiol. Oncol. 36, 131-143.

Magdolen, V., Arroyo de Prada, N., Sperl, S., Muehlenweg, B., Luther, T., Wilhelm, O.G., Magdolen, U., Graeff, H., Reuning, U., and Schmitt, M. (2000). Natural and synthetic inhibitors of the tumor-associated serine protease urokinase-type plasminogen activator. Adv. Exp. Med. Biol. 477, 331-341.

Mazar, A.P. (2001). The urokinase plasminogen activator receptor (UPAR) as a target for the diagnosis and therapy of cancer. Anti-Cancer Drugs 12, 387-400.

Monahan, P.E., and Samulski, R.J. (2000). Adeno-associated virus vectors for gene therapy: more pros than cons? Mol. Med. Today 6, 433-440.

Muehlenweg, B., Sperl, S., Magdolen, V., Schmitt, M., and Harbeck, N. (2001). Interference with the urokinase plasminogen activator system: a promising therapy concept for solid tumours. Expert Opin. Biol. Ther. 1, 683-691.

Muehlenweg, B., Assfald-Machleidt, I., Parrado, S.G., Bürgle, M., Creutzburg, S., Schmitt, M., Auerswald, E.A., Machleidt, W., and Magdolen, V. (2000). A novel type of bifunctional inhibitor directed against proteolytic activity and receptor/ligand interaction. J. Biol. Chem. 275, 33562-33566.

Negro, A., Onisto, M., Grassato, L., Caenazzo, C., and Garbisa, S. (1997). Recombinant human TIMP-3 from Escherichia coli: synthesis, refolding, physico-chemical and functional insights. Protein Eng. 10, 593-599.

Olson, M.W., Gervasi, D.C., Mobashery, S., and Fridman, R. (1997). Kinetic analysis of the binding of human MMP-2 and 9 to tissue inhibitor of metalloproteinase (TIMP)-1 and TIMP2. J. Biol. Chem. 272, 29975-29983.

Ploug, M., Gårdsvoll, H., Jorgensen, T.J., Lonborg-Hansen, L., and Danø, K. (2002). Structural analysis of the interaction between urokinase-type plasminogen activator and its receptor: a potential target for anti-invasive cancer therapy. Biochem. Soc. Trans. 30, 177-183.

Possee, R.D., Thomas, C.J., and King, L.A. (1999). The use of baculovirus vectors for the production of membrane proteins in insect cells. Biochem. Soc. Trans. 27, 928-932.

Rabbani, S.A., and Mazar, A.P. (2001). The role of the plasminogen activator system in angiogenesis and metastasis. Surg. Oncol. Clin. N. Am. 10, 393-415.

Reich, E. (1978). Activation of plasminogen: a general mecha- nism for producing localized extracellular proteolysis. In: Molecular Basis of Biological Degradative Processes (New York, USA: Berlin RD), pp. 155-169.

Reuning, U., Magdolen, V., Wilhjelm, O., Fischer, K., Lutz, V., Graeff, H., and Schmitt, M. (1998). Multifunctional potential of the plasminogen activation system in tumor invasion and metastasis. Int. J. Oncol. 13, 893-906.

Sato, S., Kopitz, C., Schmalix, W.A., Muehlenweg, B., Kessler, H., Schmitt, M., Krüger, A., and Magdolen, V. (2002). Highaffinity urokinase-derived cyclic peptides inhibiting urokinase/urokinase receptor-interaction: effects on tumor growth and spread. FEBS Lett. 528, 212-216.

Scherer, F., Schillinger, U., Putz, U., Stemberger, A., and Plank, C. (2002) Nonviral vector loaded collagen sponges for sustained gene delivery in vitro and in vivo. J. Gene Med. 4, $634-643$.

Schmiedeberg, N., Schmitt, M., Rölz, C., Truffault, V., Sukopp, M., Bürgle, M., Wilhelm, O.G., Schmalix, W., Magdolen, V., and Kessler, H. (2002). Synthesis, solution structure, and biological evaluation of urokinase-type plasminogen activator (UPA)-derived receptor binding domain mimetics. J. Med. Chem. 45, 4984-4994.

Schmitt, M., Wilhelm, O.G., Reuning, U., Krüger, A., Harbeck, N., Lengyel, E., Graeff, H., Gänsbacher, B., Kessler, H., Bürgle, M., Stürzebecher, J., and Magdolen, V. (2000). The urokinase plasminogen activator system as a novel target for tumour therapy. Fibrinol. Proteol. 14, 114-132.

Sperl, S., Mueller, M.M., Wilhelm, O.G., Schmitt, M., Magdolen, V., and Moroder, L. (2001). The UPA/uPAR System as a target for tumor therapy. Drug News Perspect. 14, 401-411.

Stamenkovic, I. (2000). Matrix metalloproteinases in tumor invasion and metastasis. Semin. Cancer Biol. 10, 415-433.

Stetler-Stevenson, W.G. (2001). The role of matrix metalloproteinases in tumor invasion, metastasis and angiogenesis. Surg. Oncol. Clin. N. Am. 10, 383-392.

Szpaderska, A.M., and Frankfater, A. (2001). An intracellular form of cathepsin B contributes to invasiveness in cancer. Cancer Res. 61, 3493-3500.

Thomas, C.J., Brown, H.L., Hawes, C.R., Lee B.Y., Min, M-K., King, L.A., and Possee, R.D. (1998). Localization of a baculovirus-induced chitinase in the insect cell endoplasmic reticulum. J. Virol. 72, 10207-10212.

Received November 12, 2002; accepted January 29, 2003 